\title{
PERANCANGAN HANDBOOK FOTOGRAFI PRODUK MENGGUNAKAN SMARTPHONE UNTUK PEMILIK BISNIS ONLINE DI KABUPATEN BANDUNG
}

\author{
Septian Riyadus Solihin ${ }^{1}$, Yosa Fiandra ${ }^{2}$ \\ Program Studi Desain Komunikasi Visual ${ }^{1,2}$ \\ Sekolah Tinggi Teknologi Bandung ${ }^{1}$ \\ Telkom University ${ }^{2}$ \\ septianriyaduss@icloud.com ${ }^{1}$, pichaq@ telkomuniversity.ac.id ${ }^{2}$
}

\begin{abstract}
Abstrak
Masalah yang sering dialami pelaku bisnis online skala mikro di Kabupaten Bandung yaitu kesulitan membuat foto produk yang menarik karena keterbatasan dana dan kurang memahami teori dasar fotografi produk mengenai konsep, angle, komposisi, pencahayaan, background, properti, editing, inspirasi, referensi serta tips dan trik memotret. Maka dibuatlah media edukasi handbook sebagai solusi dari permasalahan. Penelitian menggunakan deskriptif kualitatif dengan metode perancangan design thinking. Perancangan handbook tentang foto produk menggunakan smartphone photography diharapkan dapat menambah wawasan pelaku bisnis online mengenai cara membuat foto produk menarik dengan biaya rendah sebagai alternatif pengganti kamera profesional. Kata Kunci: Bisnis Online, Design Thinking, Foto Produk, Handbook, Smartphone Photography
\end{abstract}

\begin{abstract}
The problem that is often experienced by micro-scale online business people in Bandung Regency is the difficulty of making attractive product photos due to limited funds and lack of understanding of the basic theory of product photography regarding concepts, angles, composition, lighting, background, properties, editing, inspiration, references, tips and trick shooting. So a handbook educational media was made as a solution to the problem. This research uses qualitative descriptive with design thinking method. The design of a handbook on product photos using smartphone photography is expected to add insight to online business people on how to make attractive product photos at low costs as an alternative to professional cameras.
\end{abstract}

Keywords: Design Thinking, Handbooks, Online Business, Product Photos, Smartphone photography

\section{PENDAHULUAN}

Bisnis online adalah suatu kegiatan bisnis yang memanfaatkan media internet sebagai media pemasaran suatu produk atau jasa[22]. Dalam kegiatan bisnis online, tentu memerlukan media pendukung salah satunya yaitu foto produk. Foto produk merupakan salah satu media penting karena dapat membantu pembeli mengetahui produk apa yang ditawarkan hanya dengan melihat sebuah visual gambar. Selain itu, foto produk yang menarik dapat mempengaruhi minat pembeli terhadap suatu produk atau jasa yang ditawarkan secara online.

Menurut survei yang dilakukan oleh etsy, salah satu marketplace kerajinan terbesar di dunia "90\% pembeli mengatakan kualitas foto sangat penting dan berpengaruh terhadap keputusan pembelian"[5]. Hal ini membuktikan bahwa peran foto produk dalam kegiatan jual beli secara online sangat penting dan perlu diperhatikan.

Namun, tidak semua pelaku bisnis online, khususnya pelaku bisnis online skala mikro di Kabupaten Bandung dapat membuat foto produk yang menarik. Dari hasil observasi, mayoritas dari mereka mengaku bingung dan kesulitan membuat foto produk yang menarik karena belum mengetahui teori dasar fotografi produk. Selain itu, mereka mengaku tidak memiliki budget yang besar untuk membeli peralatan fotografi, menyewa fotografer profesional ataupun mengikuti kursus fotografi. Sebagian dari mereka juga berpendapat bahwa kompetitor mereka memiliki kualitas foto produk yang lebih baik dan menjadi ancaman karena menjadikan mereka lebih sulit bersaing.

Padahal jika mengetahui dasar fotografi produk, pemilik bisnis online dapat menghasilkan foto produk yang menarik dengan biaya rendah, yaitu dengan memanfaatkan smartphone. Cara memaksimalkan smartphone untuk menghasilkan foto produk yang menarik yaitu dengan memahami fungsi menu-menu di aplikasi kamera, membuat konsep, mengatur pencahayaan, komposisi, background dan final touch dengan melakukan editing. Maka dari itu, penting untuk memberikan edukasi tentang pengenalan teori dasar fotografi produk menggunakan smartphone.

Berdasarkan hal tersebut, maka dilakukan perancangan media edukasi untuk membantu masyarakat khususnya pemilik bisnis online skala mikro di Kabupaten Bandung. Handbook dapat menjadi salah satu media edukasi yang dapat memberikan informasi secara lengkap dan terstruktur mengenai cara membuat foto produk yang lebih menarik hanya dengan smartphone.

Diharapkan perancangan ini dapat membantu para pemilik bisnis online untuk membuat foto produk yang lebih menarik dengan biaya rendah hanya dengan smartphone sehingga mereka dapat lebih bersaing dengan kompetitor. Dengan begitu, mereka dapat lebih maju sehingga bisa meningkatkan ekonomi keluarga dan perekonomian nasional khususnya pelaku Usaha Mikro Kecil Menengah (UMKM). 


\section{LANDASAN TEORI}

\section{Fotografi Produk}

Menurut I Komang Sudarma, fotografi merupakan salah satu media komunikasi yang dapat digunakan untuk menyampaikan ide atau pesan kepada orang lain melalui media foto[7]. Pendapat lain mengatakan fotografi adalah suatu kegiatan merekam dan memanipulasi cahaya sehingga fotografer dapat menghasilkan gambar yang sesuai keinginan[11]. Fotografi atau dalam bahasa inggris photography adalah serapan bahasa yunani dari gabungan kata photos (cahaya) dan graphos (gambar) yang memiliki arti menghasilkan gambar dengan merekam cahaya[6].

Dari beberapa pengertian di atas, dapat disimpulkan bahwa fotografi secara umum adalah suatu aktivitas membuat gambar dengan cara merekam dan memanipulasi cahaya sehingga menghasilkan media yang dapat menyampaikan ide atau pesan kepada orang yang melihatnya. Salah satu genre fotografi yaitu fotografi still life, yaitu menciptakan suatu gambar dari sebuah benda mati agar terlihat lebih hidup dan berbicara, misalnya makanan yang terlihat hangat, dingin ataupun lembut. Kata still berarti benda mati atau diam, dan kata life berarti hidup, dapat memberikan konteks "tampak hidup"[14]. Salah satu cabang fotografi still life yaitu fotografi produk. Fotografi produk adalah salah satu bidang fotografi yang dikhususkan untuk mengambil gambar suatu terutama suatu produk yang nampak [15]. Menurut Kretova, fotografi produk merupakan salah satu jenis fotografi komersial yang bertujuan untuk mengenalkan produk kepada pelanggan dan bisa digunakan untuk toko online maupun portofolio, entah itu dalam bentuk cetak maupun digital[9].

\section{Dasar Fotografi Produk}

Menurut J. Dennis Thomas dalam bukunya yang berjudul The Art and Style of Product Photography, ada beberapa elemen fotografi untuk menghasilkan foto produk yang menarik dan menjual sehingga memiliki pengaruh yang kuat[8]. Antara lain:

a. Persiapan \& Peralatan

Ini merupakan tahap pra produksi. Hal yang harus dipersiapkan pertama kali yaitu konsep [13]. Untuk mendapatkan konsep sebaiknya fotografer mengetahui target audience terlebih dahulu. Konsep bisa menyangkut berbagai macam aspek, mulai dari konsep cahaya (mood), konsep properti, konsep gaya foto dan sebagainya. Cara untuk mendapat ide konsep yaitu dengan mencari banyak referensi. Setelah penentuan konsep, langkah selanjutnya yaitu pemilihan alat, meliputi kamera, lensa, tripod, background, dan properti.

b. Pencahayaan

Perihal pencahayaan, fotografer bisa menggunakan cahaya alami dari matahari (natural light) atau continuous light yaitu cahaya konstan yang berasal dari alat misalnya lampu. Selain itu, ada sumber cahaya dari flash. Yang membedakan dari continuous light yaitu flash merupakan cahaya sesaat dan aktif ketika fotografer menekan trigger. Cahaya sendiri dapat di atur menggunakan reflektor dan diffuser.

c. Exposure

Exposure merupakan pengaturan banyaknya cahaya yang masuk pada lensa. Untuk mendapatkan pengaturan exposure sempurna fotografer harus melakukan eksperimen langsung. Ada beberapa hal yang berkaitan dengan exposure, yaitu shutter speed, iso dan aperture. Tiga hal ini berbanding lurus dan saling keterkaitan.

d. Latar Belakang \& Properti

Background merupakan salah satu hal penting dalam foto produk. Fotografer bisa melakukan beberapa percobaan dan variasi dengan berbagai pengaturan yang berbeda hingga mendapatkan hasil yang maksimal.

e. Alat dan Pembersihan

Alat yang bisa digunakan seperti tape, spray bottle, air blower, glass cleaner, microfiber, cotton bud, sensor cleaning dan sejenisnya.

f. Komposisi

Komposisi secara singkat yaitu teknik menempatkan objek dan mengaturnya sehingga masuk ke dalam bingkai foto dan membuatnya lebih menarik. Ada beberapa komposisi populer yang biasanya digunakan dalam fotografi produk, antara lain:

a. Rule of Third, yaitu teknik membagi komposisi menjadi sembilan bagian dan menempatkan objek di salah satu titik.

b. Rule of odds, yaitu teori dengan menempatkan objek berjumlah ganjil dengan komposisi keseimbangan asimetris dan dinamis. Memanfaatkan mata manusia yang tertarik pada objek yang paling jelas.

c. Permainan Warna, selain dari komposisi letak fotografer bisa memainkan komposisi warna. Misal warna komplementer, analogous, gradasi, negative space.

d. Garis, pola dan tekstur, yaitu komposisi yang memainkan unsur garis, pola yang beraturan atau tekstur.

Berikutnya yaitu pengaturan angle atau sudut pengambilan gambar. Angle menyangkut dengan bagaimana kebijakan Anda menempatkan lensa. 


\section{g. $\quad$ Post Produksi}

Tahap terakhir yaitu post produksi atau dalam bahasa Indonesia pascaproduksi yaitu pemrosesan lanjutan untuk menyempurnakan hasil tangkapan kamera. Post produksi berguna untuk memperbaiki beberapa hal, seperti warna, menghilangkan noda, mengatur kembali exposure, cropping (memotong gambar) dan penyesuaian lainnya.

\section{Fotografi Smartphone}

Smartphone atau biasa disebut ponsel pintar adalah sebuah telepon seluler yang dilengkapi dengan teknologi prosesor berukuran mikro, ram, layar dan modem terintegrasi sehingga dapat melakukan fungsi layaknya seperti personal digital assistant (PDA) atau pocket personal computer (Pocket PC)[23].

Hal yang membedakan dari ponsel standar yaitu smartphone memiliki sistem operasi sehingga mampu melakukan beberapa pekerjaan seperti menelepon, bermain game, chatting, mengakses internet hingga menikmati konten multimedia [4]. Ciri smartphone modern yaitu memiliki fitur gps, sensor gerak dan kamera [23].

Karena smartphone dilengkapi kamera, maka fotografer bisa mengambil gambar dan melakukan kegiatan fotografi hanya menggunakan ponsel. Memotret menggunakan smartphone inilah yang disebut dengan smartphone photography.

\section{Pengertian Bisnis Online}

Bisnis online adalah sebuah bisnis yang di jalankan menggunakan media internet sebagai media pemasaran dari suatu produk atau jasa. Produk yang dijual bisa berupa produk fisik seperti pakaian, makanan, elektronik dan sebagainya. Produk digital meliputi $e$-book, video, audio, atau software. Selain itu ada juga produk jasa seperti jasa desain grafis, jasa penerjemah dan lain-lain [22].

\section{Media Edukasi}

Media berasal dari bahasa Latin yaitu medius yang berarti tengah, perantara atau pengantar. Secara khusus, media dalam proses belajar mengajar memiliki pengertian sebagai alat grafis, fotografis dan elektronis untuk menangkap, memproses dan menyusun kembali informasi dalam bentuk visual atau verbal [2].

Apabila media tersebut membawa sebuah pesan atau informasi yang bertujuan untuk kegiatan instruksional atau mengandung sebuah maksud pengajaran maka media tersebut disebut media pembelajaran [2]. Menurut Nurmadiah, media edukasi (educational media) atau biasa dikenal media pendidikan merupakan alat penunjang atau benda yang ditujukan untuk kegiatan pembelajaran untuk menyampaikan pesan atau informasi dari sumber kepada penerima [12].

Jadi dapat disimpulkan bahwa, media edukasi adalah suatu perantara atau alat yang dapat menyimpan informasi visual maupun verbal yang berfungsi sebagai alat penunjang dalam proses pembelajaran.

Media pembelajaran memiliki beberapa manfaat praktis, antara lain dapat memperjelas penyajian suatu pesan atau informasi sehingga memperlancar dan meningkatkan proses dan hasil belajar dan juga dapat menjadi solusi keterbatasan indera, ruang dan waktu [2]. Media edukasi dibagi menjadi tiga jenis [3], yaitu:

a. Media auditif, yaitu jenis media yang hanya mengandalkan kemampuan suara.

b. Media visual, yaitu jenis media yang hanya mengandalkan indera penglihatan.

c. Media audio visual, yaitu jenis media yang memiliki unsur audio maupun visual.

\section{Buku}

Buku adalah sebuah kumpulan lembar kertas berisi informasi, dicetak dan disusun secara tersistematis. Di bagian luarnya diberi pelindung seperti kertas tebal atau sejenisnya [20].

Kelebihan buku menurut Rustan [18], antara lain,

a. Lebih nyaman dan sehat untuk mata

b. Rangsangan seluruh panca indera memberikan dampak buku lebih mudah di ingat dari pada ebook

c. Generasi milenial mendorong tren membaca buku karena objek fisik dirasa lebih menarik seperti cover mewah, embos, UV dan sebagainya

d. Gaya hidup zaman sekarang yang suka pamer menjadikan buku sangat cocok untuk dipamerkan karena sangat instagrammable. Tidak seperti media digital

e. Buku dapat menyimpan kenangan dan emosional

Menurut Arsyad, media pembelajaran yang dicetak seperti buku dapat memenuhi kebutuhan bagi yang cepat atau lambat dalam memahami materi. Serta media cetakan dapat membuat siswa mengikuti urutan pikiran secara $\operatorname{logis}[2]$.

Salah satu jenis buku yaitu handbook. Menurut Rustan [18], handbook adalah salah satu jenis buku yang berisi ringkasan atau petunjuk untuk melakukan sesuatu pekerjaan dalam sebuah topik atau bidang tertentu. Contoh buku handbook misalnya seperti buku panduan, buku tutorial, buku do it yourself (DIY), buku pegangan dan buku manual. 
Agar buku dapat menimbulkan minat baca dan mampu menyampaikan ide yang baik terhadap pembaca, perlu memperhatikan bahasa visual dan verbal. Bahasa visual merupakan bahasa yang digunakan untuk menyampaikan pesan kepada khalayak dengan memanfaatkan media visual [21].

Menurut Rachmawati dan Ruhanda, dalam jurnal Komunikasi dan Media, media visual seperti buku panduan, brosur atau billboard terbukti efektif dan dapat menumbuhkan budaya baca bagi masyarakat [16]. Hal ini karena dipengaruhi tampilan visual seperti jenis huruf, warna, layout, gambar atau ilustrasi. Selain itu, media visual seperti gambar atau foto dapat menampilkan pokok masalah secara nyata, membatasi ruang dan waktu, solusi keterbatasan pengamatan manusia, murah, dan dapat memperjelas suatu masalah di bidang apa saja dan untuk tingkat semua usia sehingga dapat mencegah kesalahpahaman [19]. Untuk memperjelas informasi atau pesan, buku juga harus dilengkapi komunikasi verbal, menurut Kurniati [10], verbal adalah komunikasi yang bertujuan menyampaikan makna menggunakan kata-kata berupa lisan atau tulisan.

Dari uraian di atas, dapat disimpulkan bahwa handbook merupakan salah satu jenis buku yang berfungsi sebagai media penyampaian informasi berupa ide dan pengetahuan secara sistematis dan terstruktur. Handbook yang dilengkapi bahasa visual dan verbal memiliki kelebihan, antara lain:

a. Media yang sehat dan memberikan kenyamanan

b. Visual dalam buku terbukti efektif dalam menumbuhkan minat baca masyarakat

c. Dapat menampilkan masalah secara nyata

d. Menjadi solusi keterbatasan pengamatan manusia

e. Cocok untuk generasi milenial

f. Bisa dipamerkan

g. Lebih efektif untuk pembelajaran karena mudah di ingat dan memberikan kenangan dan emosi bagi pembacanya

h. Jelas bagi semua tingkat usia dan mencegah kesalahpahaman

7. Design Thinking

Menurut Yuwono, Design Thinking merupakan suatu konsep atau metode yang dapat digunakan untuk memecahkan masalah dengan mengembangkan konsep desain yang mengacu pada proses kognitif (proses berpikir), strategis (berhubungan), praktis (praktik) dengan menjadikan pengguna akhir (users) sebagai fokus utama dari solusi. Keunikan dari design thinking yaitu desainer dapat mencari terlebih dahulu suatu kebutuhan yang diinginkan target audience kemudian membuat suatu upaya pemenuhan kebutuhan [24].

\section{Layout}

Menurut Rustan, Layout dalam dunia desain memiliki arti yaitu suatu kegiatan penempatan dan penataan elemen-elemen dalam sebuah bidang agar dapat mendukung konten atau pesan yang dibawanya [18]. Dengan layout yang baik, akan dapat mempengaruhi persepsi siapapun yang melihatnya.

Adapun tahapan membuat layout cetak, yaitu creative brief, media dan spesifikasi, memilah konten, thumbnail, prototype di komputer dan test print.

a. Prinsip desain

Ada beberapa prinsip desain dalam layout, antara lain:

a. Emphasis, yaitu penekanan/penegasan berat visual pada area tertentu

b. Sequence, yaitu jalur atau urutan untuk mempengaruhi perhatian mata

c. Contrast yaitu kelompok elemen yang saling berlawanan

d. Balance, yaitu kesimbangan berat elemen visual dalam sebuah bidang

e. Unity, yaitu kecocokan, kesatuan atau keselarasan antar elemen dalam sebuah bidang

b. Tipografi

Tipografi atau huruf adalah suatu kajian mengenai penataan huruf dalam sebuah lembar halaman. Fungsi tipografi bukan hanya sekedar menyampaikan pesan, melainkan memberikan nilai estetika di dalamnya. Tipografi tidak dapat dilepaskan dari ilmu lain, seperti layout [1].

c. Konstruksi dan konten

Konstruksi yaitu terdiri dari margin (batas tepi) dan grid (column, gutter, module dan sebagainya). Konten terdiri dari teks dan gambar.

d. Anatomi buku

Anatomi buku secara garis besar terdiri dari 3 bagian, yaitu bagian depan, tengah dan bagian belakang. Tiga bagian ini terbagi lagi menjadi bagian-bagian kecil, yaitu

a. Bagian Depan; Terdiri dari halaman cover, judul, artwork, nama penulis, logo penerbit, buku terkait, penerbit, copyright page, daftar isi, daftar gambar, ucapan terima kasih dan kata pengantar.

b. Bagian Tengah; Terdiri dari halaman pengenalan, gambaran tema, cara menggunakan buku, kumpulan bab dan kesimpulan.

c. Bagian Belakang; Terdiri dari informasi tambahan, glossary, daftar pustaka, data produksi atau catatan penerbitan, kredit, biografi, cover belakang. 


\section{Media Cetak}

Media adalah suatu wadah untuk mengirimkan komunikasi dalam bentuk konten dari pengirim kepada penerima. Media cetak merupakan media yang menggunakan objek fisik. Misalnya seperti buku, majalah, koran, radio dan sebagainya [18].

\section{ANALISIS DAN PERANCANGAN}

\section{Metode Penelitian}

Penelitian menggunakan deskriptif kualitatif dengan pengumpulan data triangulasi metode. Pengambilan sampling menggunakan teknik purposive sampling dengan instrumen penelitian observasi, wawancara, document review dan kuesioner. Pengambilan data dilakukan kepada beberapa pemilik bisnis online skala mikro di Kabupaten Bandung.

2. Metode Perancangan

Untuk perancangan menggunakan metode design thinking. Ada lima tahap proses dalam proses design thinking versi Stanford, yaitu Empathize, Define, Ideate, Prototype dan Test.

\section{a. Empathize}

Tahap pertama yaitu empati, untuk mendapatkan pemahaman dari sudut pandang para pelaku bisnis online mikro di Kabupaten Bandung. Menempatkan diri sebagai pengguna ketika melakukan observasi dan wawancara, dalam hal ini yaitu sebagai pebisnis online yang membutuhkan edukasi foto produk agar mendapatkan wawasan nyata tentang masalah yang akan diselesaikan.

Membangun empati dilakukan dengan cara mengamati dan melihat langsung perilaku pengguna di kehidupan sehari-hari. Berusaha terlibat dalam kegiatan mereka dan berinteraksi langsung. Memahami dengan cara mendengarkan setiap keinginan, saran, masukan hingga keluhan mereka.

b. Define

Selanjutnya yaitu mendefinisikan apa yang menjadi kebutuhan, keinginan atau harapan pengguna sesuai data yang telah didapatkan di tahap empathize sehingga dihasilkan identifikasi masalah yang berfokus pada sisi pengguna. Proses penetapan masalah dilakukan menggunakan metode pengolahan data $5 \mathrm{~W}+1 \mathrm{H}$ dan SWOT.

c. Ideate

Pada tahapan ini, dilakukan proses kreatif dengan menghasilkan ide dan gagasan untuk memberikan alternatif penyelesaian masalah yang paling efektif sesuai dengan masalah yang telah diidentifikasi di tahap define. Dalam hal ini, dilakukan brainstorming dengan metode mind mapping.

\section{d. Prototype}

Ide dan gagasan yang telah dihasilkan di tahap ideate kemudian dituangkan dalam bentuk karya yang masih dalam tahap prototype. Karya yang dapat dilihat secara visual dan fisik berguna agar pengguna dapat berinteraksi dan memperoleh pengalaman.

Dalam perancangan karya, dilakukan dengan menggunakan teori layout dari Surianto Rustan, ada beberapa tahapan untuk membuat handbook yaitu Creative brief, pemilihan media dan spesifikasi, memilah konten, membuat thumbnail, prototype di komputer, terakhir melakukan test print.

e. Test

Tahap terakhir yaitu menguji coba produk atau karya yang telah dibuat kepada pengguna (target audience). Ini bertujuan untuk melihat respon target audience sehingga didapatkan data berupa masukan dan saran. Data kemudian dikumpulkan untuk dijadikan dasar dalam melakukan evaluasi dan revisi pada media edukasi yang telah dibuat sesuai dengan masukan dari pengguna.

\section{Metode Analisis Data}

Setelah informasi dan data telah diperoleh melalui hasil observasi, wawancara, kuesioner dan document review, selanjutnya dilakukan analisa data lewat beberapa tahap. Pertama yaitu mengolah data dengan menggunakan analisis $5 W+1 H$ dan $S W O T$. Kedua yaitu menyederhanakan jawaban responden dengan mereduksi atau merangkum data yang berkaitan dengan perancangan. Ketiga yaitu pemaparan data menjadi sekumpulan informasi. Dan yang terakhir yaitu proses penarikan kesimpulan.

\section{HASIL DAN PEMBAHASAN}

Dari hasil observasi, ditemukan beberapa kendala yang dialami para pebisnis online di wilayah kabupaten bandung yaitu masalah angle, komposisi, cahaya, properti, tempat, editing, inspirasi dan referensi. Mereka juga membutuhkan pengenalan fungsi setiap menu pada aplikasi kamera smartphone. 


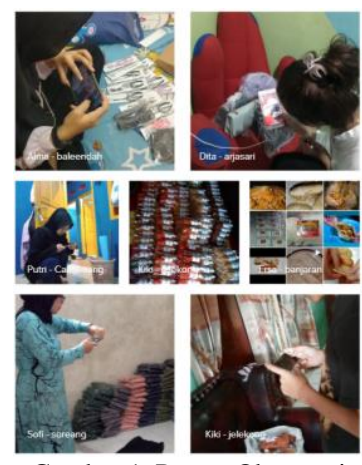

Gambar 1. Proses Observasi

Sumber: Dokumentasi Pribadi

Untuk mendapatkan informasi lebih dalam, dilakukan juga wawancara kepada narasumber yang relevan dan memiliki pengalaman di bidang fotografi produk, didapatkan hasil bahwa saat memang banyak pebisnis online pemula yang asalasalan dalam membuat foto produk dan tidak memaksimalkan peralatan yang ada. Untuk membuat foto produk menarik bisa dengan memanfaatkan sumber cahaya alami maupun cahaya buatan seperti lampu belajar, LED, kardus dengan neon atau membeli lightbox yang murah. Kemudian bisa memanfaatkan background hitam dan putih, karton bertekstur, dan memanfaatkan alat di rumah berdasarkan konsep produk. Perlu juga memperhatikan point of view dan konsep. Buku bagus untuk mengedukasi mereka karena buku yang dicetak lebih nyata dirasa, dipegang, mudah di bolak-balik serta di catat dengan alat tulis di bagian tertentu.

Berdasarkan hasil kuesioner kepada 109 responden ditemukan bahwa mayoritas merupakan perempuan dengan rentan usia terbanyak yaitu 18-25 tahun. Berdasarkan usia bisnis, mayoritas di bawah 1 tahun dan produk yang paling banyak dijual yaitu sandang, pangan dan produk kecantikan. Mereka menggunakan media sosial, aplikasi instant messaging dan marketplace sebagai media berjualan online, dengan traffic yang di dapat dari database (kontak atau kenalan), organik lewat media sosial serta memanfaatkan iklan. Semua responden mengaku bahwa mereka menggunakan foto produk, namun mayoritas tidak memiliki peralatan foto produk profesional. Mereka mengaku tidak memiliki budget untuk membeli alat fotografi profesional ataupun mengikuti pelatihan fotografi. Mayoritas responden juga mengaku bahwa mereka tidak pernah mendapatkan edukasi mengenai fotografi dasar. Padahal mereka mengetahui bahwa foto produk menarik dapat menarik minat konsumen. Mereka juga mengaku bahwa kompetitor mereka memiliki foto produk lebih menarik sehingga ini menjadikan sebuah ancaman bagi mereka. Mereka tidak bisa menghasilkan foto produk karena merasa bingung dan kesulitan. Mereka membutuhkan materi edukasi foto produk yang hemat dan bersedia mengeluarkan uang 100 ribu hingga 500 ribu. Dilihat dari kebiasaan, mayoritas dari mereka mengaku senang membaca buku dan berpendapat bahwa buku merupakan salah satu media yang efektif.

1. Analisis SWOT

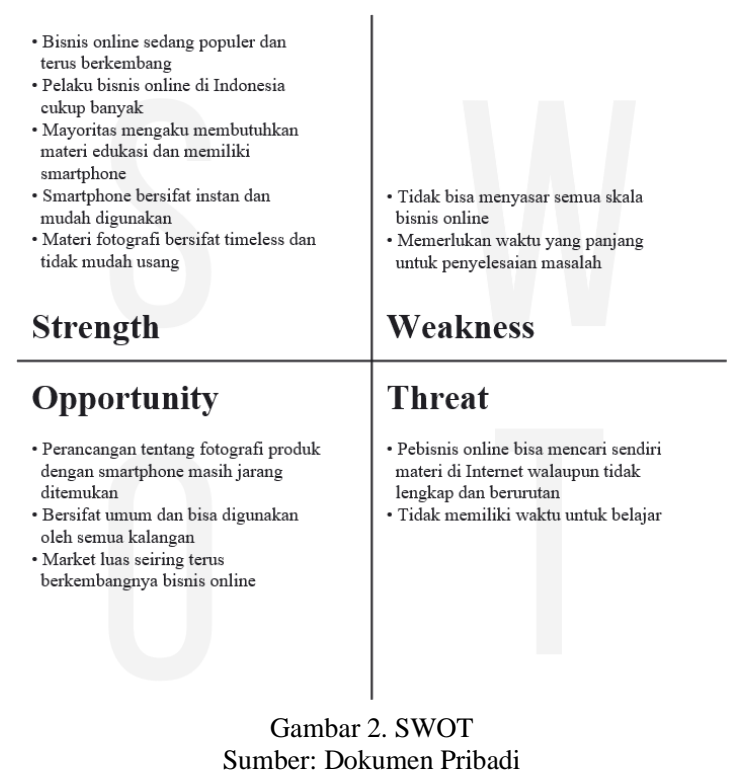

2. Analisis $5 W+1 H$

Sumber: Dokumen Pribadi

a. What; Banyak pebisnis online pemula yang baru memulai mengaku kesulitan dan bingung dalam membuat foto produk. Mereka juga mengaku bahwa kompetitor memiliki kualitas foto lebih menarik sehingga menjadi sebuah ancaman karena mereka sulit bersaing. Mereka tidak memiliki budget untuk membeli peralatan fotografi profesional atau mengikuti kursus fotografi. 
b. Who; Pelaku bisnis online pemula yang baru memulai dengan skala bisnis UMKM yang menggunakan platform marketplace, media sosial dan instant messaging sebagai media jualan.

c. Where; Masalah ditemukan di beberapa wilayah Kabupaten Bandung.

d. When; Ketika pemilik bisnis online membuat foto produk sendiri untuk media penunjang berjualan online.

e. Why; Karena para pemilik bisnis online belum mendapatkan edukasi mengenai dasar fotografi dan belum mengetahui cara memaksimalkan peralatan yang ada yaitu smartphone. Dengan edukasi foto produk, maka mereka diharapkan dapat lebih bersaing dengan kompetitor dan dapat meningkatkan taraf ekonomi keluarga khususnya pemilik bisnis online.

f. How; Dengan membuat handbook fotografi produk menggunakan smartphone sebagai salah satu bentuk penyelesaian.

3. Konsep Perancangan

Menghadirkan materi berupa teori dan panduan teknis "step by step" membuat foto produk dengan smartphone dari mulai tahap pengenalan, praproduksi, produksi, dan pascaproduksi yang dikemas dengan bahasa yang sederhana dan dilengkapi ilustrasi gambar sehingga lebih mudah dipahami target audience.

a. Segmentasi

Agar hasil perancangan lebih terarah dan efektif maka perancangan ini lebih ditujukan untuk kelompok berikut.

a. Demografis

Jenis Kelamin : Laki-laki dan Perempuan

Usia $\quad:$ 18-35 Tahun

SES $\quad:$ Kelas B ke bawah (Pengeluaran $<$ Rp. 3.000.000/bulan)

Profesi : Pemilik bisnis online

Skala UMKM : Mikro

b. Geografis; Kabupaten Bandung

c. Psikografis: Menggunakan internet dan aktif di media sosial, Kreatif dan produktif, Rasa ingin tahu yang tinggi, Menggunakan salah satu flatform marketplace, media sosial atau instant messaging, Senang membaca buku, Menyukai bisnis online

b. Targeting

Perancangan ini ditujukan untuk para pemilik bisnis online atau pekerja yang memiliki usaha sampingan bisnis online dengan skala bisnis mikro, terutama yang menggunakan marketplace, media sosial dan instant messaging sebagai media untuk berjualan. Berusia 18-35 tahun dan memiliki minat tinggi terhadap bisnis online. Target ini dipilih karena mereka yang memiliki minat dan rasa ingin tahu dalam bisnis online, mempunyai antusias dan semangat dalam belajar, termasuk bagaimana membuat foto produk yang dapat meningkatkan minat pembeli.

c. Positioning

Memperkenalkan materi yang dapat membuat foto produk para pelaku bisnis online lebih menarik, berupa teori dan panduan teknis "step by step" membuat foto produk "low budget" dengan menggunakan smartphone dari mulai tahap praproduksi, produksi, hingga pascaproduksi.

\section{Strategi Komunikasi}

Penyampaian materi edukasi dilakukan melalui media yang sesuai permintaan, memungkinkan dan hadir dalam keseharian target audience. Diketahui dari hasil kuesioner dan consumer journey. Pendekatan melalui komunikasi verbal dan visual. Verbal berupa tulisan materi yang sesuai dengan gaya bahasa yang disukai target audience dan visual berupa ilustrasi foto dan gambar untuk mempermudah target audience memahami isi materi.

5. Strategi Kreatif

Menggunakan behind the scenes, tambahan insert box, tips dan trik foto berbagai jenis produk, ngulik cara memaksimalkan kamera smartphone, aturan marketplace, step by step, memaksimalkan software editing.

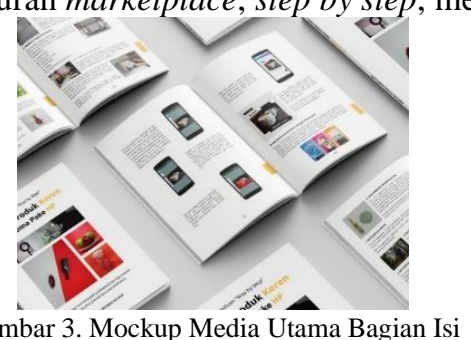

Gambar 3. Mockup Media Utama Bagian Isi

Sumber: mockups-design.com (free for commercial license) 


\section{Konsep Verbal}

Mayoritas target audience lebih menyukai gaya bahasa sehari-hari yang tidak terlalu baku namun tetap menggunakan bahasa Indonesia yang baik. Maka materi akan dikemas dalam bahasa Indonesia dengan penggunaan kata-kata sehari-hari seperti kamu, kita dan bahasa populer sejenis.

\section{Konsep Visual}

Dalam perancangan ini, penyampaian materi akan ditunjang dengan ilustrasi berupa foto agar pembaca dapat lebih mudah memahami isi materi. Menggunakan layout sederhana dengan menerapkan beberapa prinsip desain. Dalam perancangan ini, tone and manner yang ingin ditampilkan yaitu:

Visual : Simpel, elegan, inspiratif dan rapi

Verbal : Bahasa Indonesia dan tidak terlalu baku

a. Tipografi

Mayoritas target audience lebih menyukai jenis typeface sans serif, maka dipilihlah font Source Sans Pro yang merupakan salah satu desktop font yang dirancang untuk tampil baik di komputer dan optimal ketika dicetak. Dipilih berdasarkan kualitas huruf (legibility) dan keterbacaan (readability).

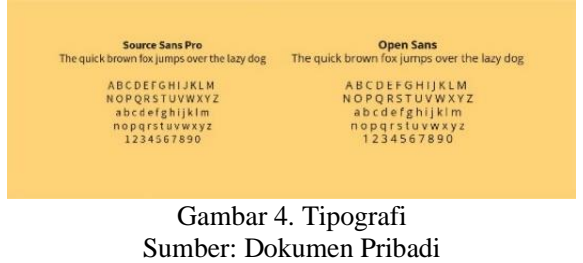

b. Tata letak

Sumber: Dokumen Pribadi

Penataan tata letak sederhana dan rapi, namun tetap menggunakan beberapa teori desain untuk memberikan nilai keindahan serta keterbacaan yang baik. Seperti penegasan berat visual (emphasis), alur baca (sequence), kontras, keseimbangan serta kesatuan.

c. Warna

Karena untuk keperluan media cetak, maka menggunakan warna $C M Y K$. Putih sebagai latar belakang, agar memberikan keterbacaan dan kontras yang baik. Selain itu agar memberikan kesan bersih dan rapi. Kuning dengan dan oranye dipilih sebagai warna kedua, karena menurut Rustan (Rustan, 2019)[17], warna ini dapat membangkitkan semangat, rasa senang, kegembiraan dan antusiasme sehingga diharapkan dapat memberi inspirasi dan motivasi pembaca ketika melihat buku. Warna selanjutnya yang dipilih yaitu hitam yang lembut serta abu kebiruan agar memberikan kontras yang baik serta memberi kesan elegan.
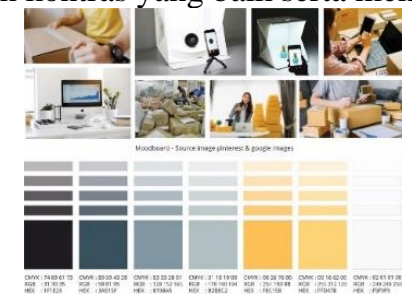

Gambar 5. Mood Board dan Palet Warna Sumber: Dokumen Pribadi

d. Garis dan Bentuk

Garis dan bentuk yang digunakan memiliki sudut tegas, agar terlihat rapi dan simpel. Melambangkan kepastian, keyakinan, dan ketegasan. Terinspirasi dari bentuk kotak paket yang biasa digunakan oleh pelaku bisnis online. Selain itu, garis-garis juga terinspirasi dari tarikan lakban yang lurus dan tegas. Bentuk bulat dan segitiga terinspirasi dari bentuk lensa kamera smartphone dan elemen grafis yang biasa ada di situs jual beli online.

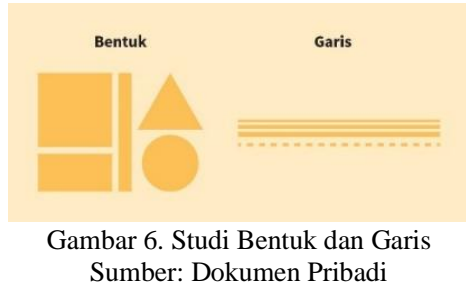

e. Thumbnail dan cover

Sumber: Dokumen Pribadi

Gambar thumbnail pada cover menggunakan ilustrasi foto yang menggambarkan isi dari buku. Foto yang dipilih merupakan foto yang di anggap paling menarik sehingga dapat meningkatkan minat beli. 


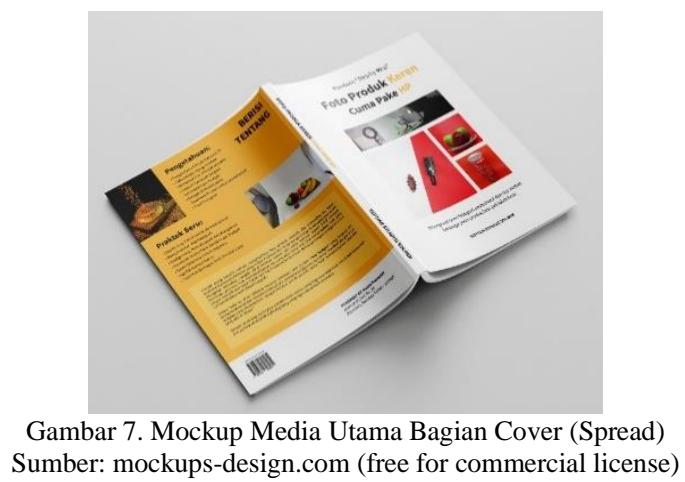

8. Creative Brief

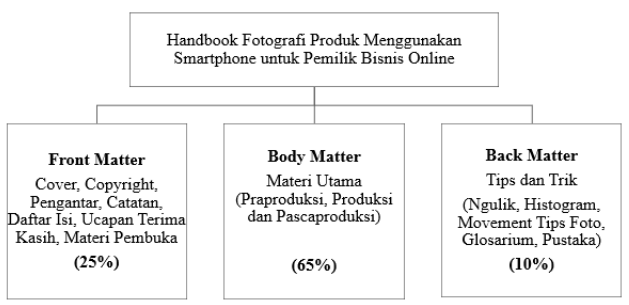

Gambar 8. Proses Observasi

Sumber: Dokumentasi Pribadi

Pembagian persentase ini didapatkan dari hasil survei kepada target audience didapatkan hasil bahwa mereka membutuhkan materi dasar fotografi sehingga ini menjadi konten yang paling di tonjolkan sekaligus kelebihan dan daya tarik dari perancangan ini. Selain itu ada tambahan materi sesuai kebutuhan seperti pengetahuan umum mengenai bisnis online dan fotografi serta tips dan trik tambahan sebagai solusi pelengkap.

\section{Konsep Kreatif}

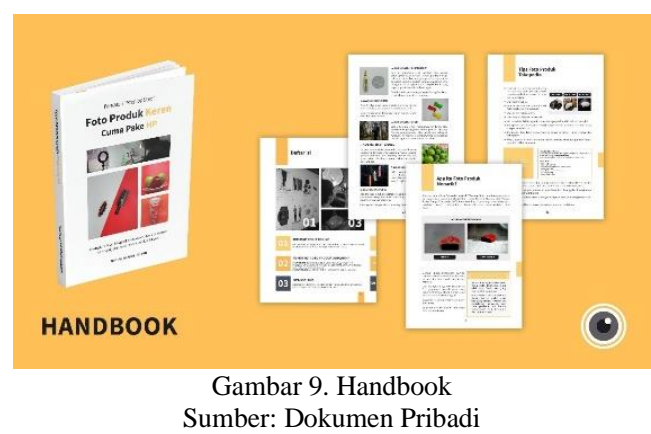

Penyampaian materi berupa panduan step by step fotografi produk, dilengkapi juga pengetahuan umum mengenai bisnis online dan tips trik foto berbagai jenis produk. Menggunakan konsep desain elegan melalui warna yang kalem, tata letak simetris, tipografi yang rapi dan mudah dibaca, serta visual real picture melalui ilustrasi foto dengan gaya bahasa penyampaian materi yang tidak terlalu baku namun tetap menggunakan bahasa Indonesia yang baik.

10. Visualisasi

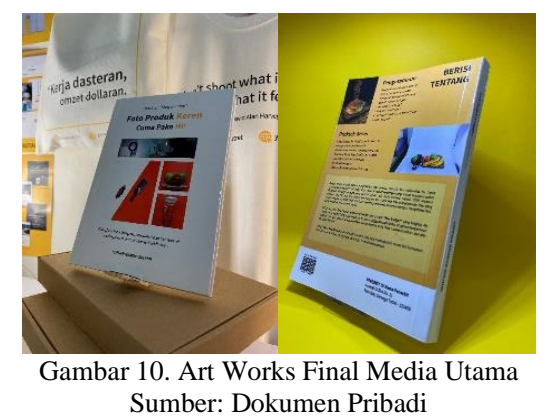

Spesifikasi

a. Ukuran Handbook: A5

b. Bahan Sampul: Art paper 210 gsm 
c. Laminasi: glossy

d. Bahan Isi: Matte paper dua sisi

e. Sampul: Soft Cover

f. Print: Full colour

\section{KESIMPULAN}

Berdasarkan hasil penelitian, pemilik bisnis online skala mikro di Kabupaten Bandung membutuhkan edukasi mengenai dasar fotografi produk untuk dapat membuat foto produk yang menarik. Smartphone merupakan salah satu solusi alternatif membuat foto produk menarik yang instan dengan biaya yang rendah. Materi yang dibutuhkan meliputi pengenalan menu kamera smartphone, konsep, angle, komposisi, pencahayaan, background, properti, editing, inspirasi, referensi serta tips dan trik.

Dari hasil proses perancangan dengan metode design thinking, mendapat sebuah ide dan gagasan yaitu membuat handbook sebagai media edukasi agar pemilik bisnis online mikro di Kabupaten Bandung mengetahui dan memahami bagaimana membuat foto produk dengan smartphone photography sebagai alternatif pengganti kamera profesional.

Hasil test menghasilkan wawasan bahwa komunikasi visual dan verbal dengan penerapan prinsip dasar desain melalui penggunaan tata letak sederhana yang rapi, warna kontras, jenis huruf sans serif, foto ilustrasi dan bahasa sederhana yang tidak terlalu baku dapat mempermudah pembaca dalam memahami materi dalam handbook.

\section{REFERENSI}

[1] Anggraini, L., \& Nathalia, K. (2016). Desain Komunikasi Visual. Nuansa Cendekia.

[2] Arsyad, A. (2020). Media Pembelajaran (Revisi,-C). PT RAJAGRAFINDO PERSADA.

[3] Aryni, Y., \& Supiatman, L. (2020). PENGUASAAN KOSAKATA SISWA SD SWASTA AN NAHLU KISARAN DENGAN MENGGUNAKAN MEDIA AUDIOVISUAL

[4] Choi, S. W., Kim, D. J., Choi, J. S., Ahn, H., Choi, E. J., Song, W. Y., Kim, S., \& Youn, H. (2015). Comparison of risk and protective factors associated with smartphone addiction and Internet addiction. Journal of Behavioral Addictions, 4(4), 308-314. https://doi.org/10.1556/2006.4.2015.043

[5] Combs, T. (2017). Showcase Your Products With More Images and Larger Image Sizes. Etsy. https://www.etsy.com/sellerhandbook/article/showcase-your-products-with-more-images/158634470078

[6] Enche Tjin, \& Erwin Mulyadi. (2014). Kamus Fotografi. Elex Media https://books.google.co.id/books?id=GN1MDwAAQBAJ\&dq=fotografi+adalah\&lr=\&hl=id\&source=gbs_navlinks_s

[7] I Komang Sudarma. (2014). Fotografi. Graha Ilmu.

[8] J. Dennis Thomas. (2013). The Art and Style of Product Photography. John Wiley \& Sons.

[9] Kretova, A. (2013). Product Photography for an Online Store and a Printed Catalog. In Thesis. Helsinki Metropolia University of Applied Sciences (Nomor November). http://urn.fi/URN:NBN:fi:amk-2013120419967

[10] Kurniati, D. P. Y. (2016). Modul Komunikasi Verbal Dan Non Verbal. 13.

[11]Marcus Sudjojo. (2010). Tak Tik Fotografi - Marcus Sudjojo - Google Buku. Bukune. https://books.google.co.id/books?id=rz9k8WE53MUC\&dq=fotografi+Marcus+Sudjojo\&lr=\&hl=id\&source=gbs_navlinks_s

[12]Nurmadiah, N. (2016). Media Pendidikan. Al-Afkar : Jurnal Keislaman \& Peradaban, 5(1). https://doi.org/10.28944/afkar.v5i1.109

[13]Octavia, A. (2018). Smartphone Photography (T. Rafiantika (ed.)). Gagas Media. https://books.google.co.id/books?id=0_VaDwAAQBAJ\&lpg=PP1\&dq=. Smartphone Photography Foto Kece Cuma Pakai HP\&hl=id\&pg=PP5\#v=onepage\&q=. Smartphone Photography Foto Kece Cuma Pakai HP\&f=false

[14]Paulus, E., \& Lestasi, L. I. (2012). Buku Saku Fotografi: Still Life. Elex Media Komputindo.

[15]Purwanto, Y., \& Veranita, M. (2018). Pelatihan Fotografi Dasar Bagi Pelaku Usaha Kecil Dan Menengah ( Ukm ) Kecamatan Lengkong Kota Bandung. 02(02), 205-211.

[16]Rachmawati, T. S., \& Ruhanda, H. (2017). Efektifitas Penggunaan Media Komunikasi Dalam Rangka Sosialisasi Program Gpmb (Gerakan Pembinaan Masyarakat Baca) Di Jawa Barat. Commed: Jurnal Komunikasi dan Media, 2(1), 25. https://doi.org/10.33884/commed.v2i1.235

[17]Rustan, S. (2019). Warni. PT Linstas Kreasi Imaji.

[18]Rustan, S. (2020). Layout 2020 (2020 ed.). CV. Nulisbuku Jendela Dunia.

[19] Sadiman, A. S., \& dkk. (1990). Media Pendidikan (Cetakan 2). CV Rajawali.

[20]Sitepu, B. P. (2012). Penulisan buku teks pelajaran. PT. Remaja Rosdakarya.

[21]Talani, N. S. (2014). Gaya bahasa visual kartun editorial. 694-701.

[22]Timothi, J. (2010). MEMBANGUN BISNIS Online $\& \mathrm{hl}=\mathrm{id} \& \mathrm{pg}=\mathrm{PR} 3 \# \mathrm{v}=$ onepage \&q=Timothy, James. 2010. Membangun

[23] Williams, B. K., \& Stacey C, S. (2010). Praise from Reviewer of Previouse Editions of Using Information Technology:A Practical Introduction to Computer \& Communications.

[24] Yuwono, A., \& Indrajit, R. E. (2020). Pengantar Design Thinking. ANDI. 